\begin{tabular}{|c|c|c|}
\hline $\begin{array}{c}\text { PORT SAID ENGINEERING RESEARCH JOURNAL } \\
\text { Faculty of Engineering - Port Said University } \\
\text { Volume 17 No.1 pp: 175:179 }\end{array}$ & \\
\hline
\end{tabular}

\title{
STRENGTH ASSESSMENT OF AGED FORE-END TRANSVERSE BULKHEAD IN BULK CARRIERS
}

\author{
M.A. Mosaad ${ }^{\text {, }}$ H. S. El- Kilani ${ }^{2}$, R. Ramadan ${ }^{3}$ and M. Attia ${ }^{4}$
}

\begin{abstract}
Ship structures while in service are likely to be subjected to age deterioration which had actually caused catastrophic structural or total loss especially for bulk carriers. This had implied the need to develop advanced technologies which can allow for proper management and control of such age related deterioration. Recently, IMO and class societies have developed rules and regulations utilizing risk-based methods. The Formal Safety Assessment (FSA) is an example of such developments. In this paper a finite element model has been established by using ship structural analysis program for fore-end bulkhead of an existing bulk carrier which is being subjected to SOLAS XII as a risk control option of formal safety assessment. The main aim of the finite element model is to assess the strength characteristics of the structural members during service time with the reduction of bulkhead plating thickness due to age deterioration according to a recommended corrosion model and estimated corrosion rates. The insights developed from the present study are useful for finding a proper management for structural repair with consideration of corrosion wastage.
\end{abstract}

\section{INTRODUCTION}

Recently, aged bulk carriers suffered many types of structural problems. Corrosion and fatigue cracking are clearly the most pervasive types of problems which can potentially lead to catastrophic failures or unanticipated out of service time if not properly repaired or rectified [1]. Inspections are a key issue in ensuring the safety of aged ships. Inspection intervals, inspection methods and reliability should be considered. The Enhanced survey program (ESP) is a current practice for condition assessment of bulk carriers, which is developed on the basis of a critical evaluation of ship structures together with an appreciation of current experience with corrosion and cracking. The ESP is also based on the need to make quite transparent and specific procedures to avoid loopholes that could lead to insufficient follow up [2]. In some cases, the activities of inspection or repair are not enough, while they are excessive in other cases. IMO has developed Formal Safety Assessment (FSA) which is a rational and systematic process for assessing the risks associated with shipping activity and for evaluating the costs and benefits for reducing these risks [3]. SOLAS Chapter XII Regulation 6 is one of the FSA recommendations which mandate that the transverse watertight bulkhead between the two foremost holds in bulk carriers shall have sufficient strength to withstand flooding of the first hold [4].

In the present study, a finite element analysis has been established for the fore-end bulk head in a single deck

\footnotetext{
${ }_{, 2,3}$ Professor, Assoc. professor and lecture in Naval Architecture and Marine Engineering Department, Faculty of Engineering, Port Said University, Port Said, Egypt.

4 B.Sc. Naval Architecture and Marine Engineer, E-mail: Mahmoudattiaya140@hotmail.com.
}

bulk carrier affected by SOLAS Chapter XII Regulation 6 (existing ship).

\section{FORMAL SAFETY ASSESSMENT FOR FORE-END BULKHEAD}

The Maritime Safety Committee (MSC) at its seventyfourth session (2001) and the Marine Environment Protection Committee (MEPC) at its forty-seventh session (2002) approved Guidelines for FSA for use in the IMO rule-making process [3]. FSA is a method to comparatively evaluate the components in proposed new regulations or to compare standards. FSA allows for a cost-risk-benefit comparison to be made between the various technical issues, including human factors. The FSA approach is based on the recognition that many risks arise from multiple causes (i.e. from system behavior) and can be mitigated in a variety of ways. This view leads to the approach of allowing safety to be based on the most cost effective risk control option (RCO) rather than on some prescribed standard, one-size-fits-all approach. This is especially beneficial for innovative designs, where the standard approach to reduce risk may not be optimal. The analysis of historical data from 1978 to 1998 revealed that casualties may be attributed to structural failure accounted for approximately $74 \%$ of all casualty related fatalities on bulk carriers larger than 20,000 DWT [5].

The basic risk from water ingress scenarios are estimated, as this constitutes the major contributor to the overall fatality risk from "structural failure". The following scenarios leading to water ingress have been assessed to establish base risk levels to be used when evaluating risk control options:

1. Side shell failure scenarios. 
2. Fore end flooding scenarios.

3. Hatch covers failure scenarios.

In November 1997 (IMO) adopted a new Chapter XII on bulk carrier to the International Convention for the Safety of Life at Sea (SOLAS) 1974 as a risk control option RCO for fore-end flooding scenarios. The new rules cover survivability and structural requirements for bulk carriers of 150 meters and upwards to prevent them from sinking if water enters the ship for any reason. IMO also adopted revised guidelines on enhanced surveys of bulk carriers and a code of practice for safer loading and unloading that may be summarized in the following points:

\section{Stronger new ships:}

Increase the strength of transverse bulkheads and the double bottom to withstand hold-flooded conditions.

2. Existing ships:

The bulkhead between holds 1 and 2 and the double bottom of hold 1 must be strengthened to withstand flooding in hold 1, as shown in Fig.1, unless loading restrictions are imposed.

3. Restrictions on carriage of cargoes:

Existing bulk carriers which meet the new structural requirements by means of loading restrictions must be marked with a solid equilateral triangle on the hull amidships below the deck line.

4. Loading instrument equipment to be fitted to monitor the stresses during loading and unloading operations.

5. Enhanced surveys program of inspections to detect potential structural weakness and areas of corrosion.

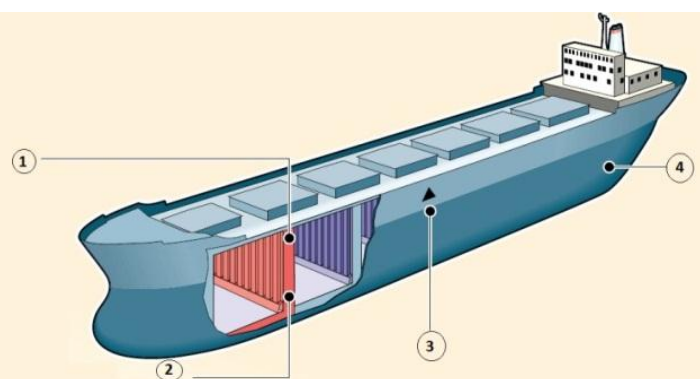

Fig. 1: Risk control options (SOLAS, Chapter XII)[4]

\section{MECHANISMS OF AGE RELATED DETERIORATION}

Ship structural life is determined mainly by the progress of corrosion and fatigue. Rational repair based on an accurate assessment of remaining life and the development of materials with resistance to corrosion and fatigue are key issues for reduction of the life cycle cost of operating ships.

Corrosion and corrosion-related problems are considered to be the most important factors leading to age-related structural degradation of ships and many other types of steel structures. Corrosion has a harmful consequence from the point of view of safety and can lead to thickness penetration, fatigue cracks, brittle fracture and unstable failure.

\subsection{Corrosion wastage models.}

General corrosion is the most common one which is theoretically evenly spread over the surface of the metal. Various models of corrosion deterioration have been proposed recently as summarized in Fig.2. The first model as given by Southwell et al. (9) considers that the same coating life and the corrosion rate becomes zero at the same exposure period. From the model given by Soares \& Garbatov (9), the time-variant corrosion wastage is divided into three different phases; the first phase is assuming no corrosion due to the corrosion protection system. After the corrosion protection is damaged, the second phase is initiated and a decrease in the thickness of the plate starts. The third phase corresponds to a stop in the corrosion process because the corroded material stays on the plate surface protecting it from contact with the corrosive environment. The third model introduced by Qin \& Cui (9), assumed that the coating protection system deteriorates gradually, and then the pitting leads to early corrosion. In the last stage, the corrosion rate becomes zero. In the fourth model of Paik et al. (9), a second transition stage between the breakdown of the corrosion protection system and the start of the corrosion is introduced and assumed to follow a lognormal distribution. A concave, convex or linear curve could be the corrosion loss curve for the third phase. The model of Ivanov (2004)(9) assumed that the second phase is a gradual acceleration of corrosion after the coating breaks down, and the corrosion rate reaches its maximum in the final phase.

\subsection{Estimation of corrosion rates in transverse bulkheads in bulk carriers}

Watertight transverse bulkheads in bulk carriers may be susceptible to accelerated corrosion, particularly at the mid-height and at the bottom. Corrosion was found distributed fairly uniformly over transverse bulkheads, with $20-25 \%$ wastage of original thicknesses corresponding to a wastage rate of 0.3 to $0.4 \mathrm{~mm}$ per year. In the worst cases, however, wastage rates are $35 \%$ (equivalent to 0.5 to $0.6 \mathrm{~mm}$ ) per year [12].

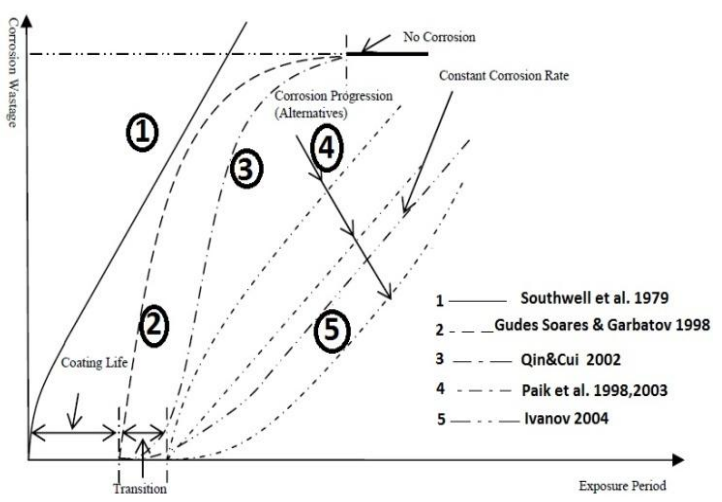

Fig. 2. Corrosion wastage models [11] 


\section{MODEL DESCRIPTION}

The aim is to generate a finite element model by using a commercial software (ANSYS), that would give best possible predictions of the fore end bulkhead strength with reduction of bulkhead plating thickness according to the corrosion rate model of Paik, 2003[10] and estimated corrosion rates $0.35 \mathrm{~mm} /$ year as mentioned in the DNV casualty report [11]. For simplicity, it is assumed that coating effective period is five years.

The applied loading consists of the lateral pressure exerted by the cement cargo and ingress water in hold No. 1, when flooded, and the pressure exerted by the surrounding seawater [4].

Table.1. Candidate ship data

\begin{tabular}{ll}
\hline NAME OF VESSEL & \multicolumn{1}{c}{ ROCK EXPRESS 1 } \\
Type of vessel & Single deck bulk carrier \\
Date of built & 1978 \\
Length O.A & $192.57 \mathrm{~m}$ \\
Length B.P & $187.50 \mathrm{~m}$ \\
Breadth & $30.00 \mathrm{~m}$ \\
Depth & $15.40 \mathrm{~m}$ \\
Gross tonnage & 24589 \\
Net tonnage & 14702 \\
\hline
\end{tabular}

The transverse bulkhead consists of the following parts:

1. Lower stool

2. Upper stool

3. Corrugations

4. Stiffened plates

The finite element mesh is performed using parametric and free-mesh options in order to obtain a fine mesh at the areas of interest. The shell elements used for the modeling are four-node quadrilateral (Shell 4T) and three-node triangular (Shell 3T). Four-node elements use a full integration scheme based on a variation of the Assumed Strain Method, used for their accuracy and convergence, in both linear and non-linear applications. Three-node elements are used in order to reduce the integration scheme [13].

Only one kind of steel is used for the model under consideration according to the requirements of Germanischer Lloyd rules (2008). The material considered is mild steel Grade " $A$ ", yield stress 235 $\mathrm{MPa}$, Young's modulus $210 \mathrm{Gpa}$, Poisson's ratio 0.3.

One of the most serious tasks related to the proper modeling of ship structures using finite elements is the definition of the boundary conditions. Especially in the case of modeling entire parts of ships, incorrect boundary conditions may introduce considerable errors by suppressing the deformation of the cross sections at which they are applied or by giving rise to deformation modes that are not realistic. In the present case study, the boundaries of the modeled fore-end bulkhead are shown in Fig. 3 as listed below:

1. Upper stool and main deck.

2. Lower stool and double bottom.
3. Stiffened plates and side shell.

4. Stiffened plates and hopper tanks.

5. Stiffened plates and top side tanks.

All the boundaries mentioned are considered fixed with zero degree of freedom.

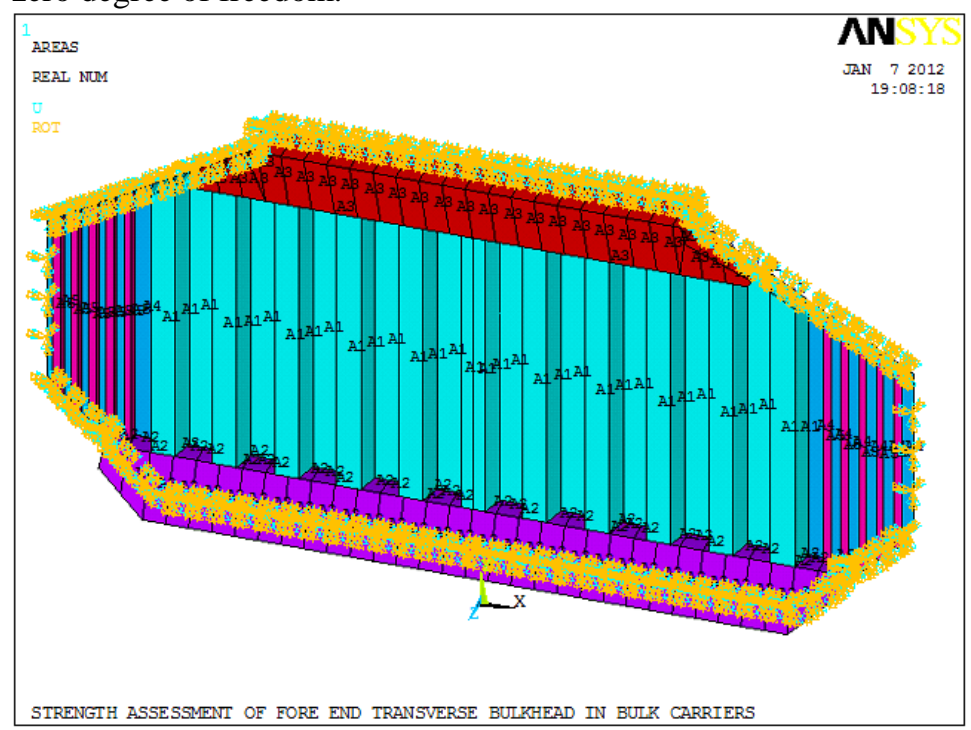

Fig. 3. View of the fore-end bulkhead model

\subsection{Load calculation}

The loads applied are defined in such a way as to examine that an actual structure constructed according to the regulations for the first hold may withstand the combined ingression water and load pressure. According to CSR (Comment Structural Rules), this combined pressure $\left(\mathrm{P}_{c}\right)$ on the corrugations is given according to the following calculations.

In Fig. 4 the flooding head $h_{f}$ is the distance $(m)$ measured vertically with the ship in the upright position, from the calculation point $P$ to a level located at a distance $d_{f}(m)$ from the baseline. For the particular vessel $d_{f}$ is taken equal to the depth $\mathrm{D}$ considered from the baseline to the freeboard deck at side amidships, while $d_{f}$ is the flooding head measured from the baseline, $d_{1}$ is the distance $(m)$ from the baseline up to the level where there is both cargo and ingression water. Since $d_{f}$ is greater than $d_{1}$, the following equations are used to give the pressure on the corrugations as the particular vessel is fully loaded [9]:$$
P_{c}=\rho \cdot g \cdot h_{f}+\left(\rho c-\rho(1-\text { perm }) g \cdot h_{1} \cdot n\right.
$$$$
\rho=1.025\left(\mathrm{t} / \mathrm{m}^{3}\right)
$$$$
\rho_{c}=\text { bulk cargo density }\left(t / \mathrm{m}^{3}\right)
$$$$
\mathrm{h}_{1}=\text { vertical distance }(\mathrm{m}) \text {, from the calculation point to }
$$$$
\text { horizontal plane corresponding to the volume of the }
$$$$
\text { cargo }
$$$$
\mathrm{n}=\tan ^{2}\left(45^{\circ}-\delta / 2\right)
$$$$
\delta=\text { angle of repose of the cargo (taken } 25^{\circ} \text { for cement) }
$$$$
\text { perm }=\text { permeability of cargo (taken } 3 \text { for cement). }
$$ 


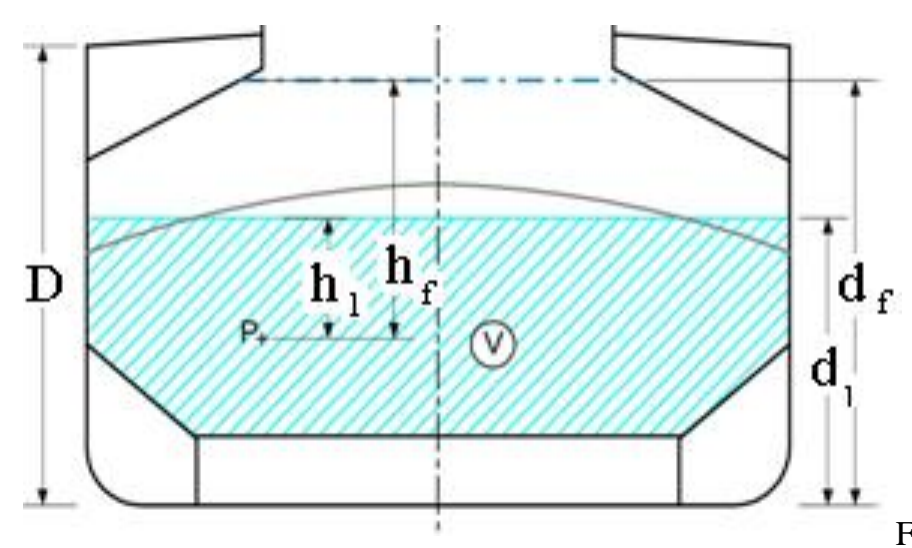

Fig.4. Transverse section of a bulk carrier in the flooded condition [9]

The pressure distribution on each node is then obtained in $\mathrm{N} / \mathrm{m}^{2}$.

\subsection{Discussion of results}

In this section, the results obtained for the pressure level prescribed by GL - 2008 are presented. These results are in general Y-component stress plots for the structural part considered. Fig. 5 presents the output stress for the original bulkhead thickness which shows that the maximum stress is located at the middle height of the corrugation and stiffened portions. Similar runs had been carried out for the bulkhead with the reduced thickness after 12 years and after 20 years showing the gradual rate of stress increase due to the deduction of plating thickness.

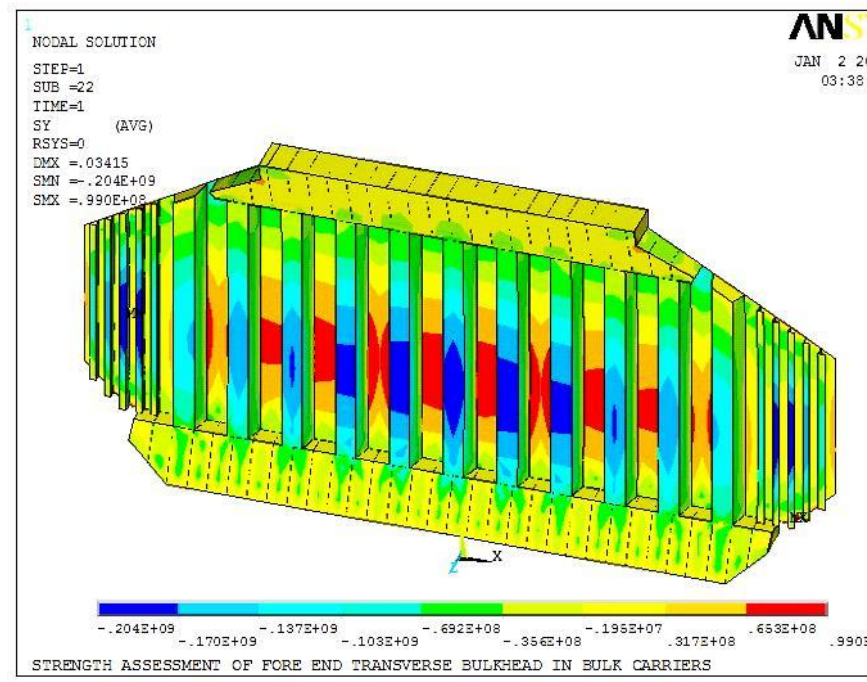

Fig.5. Stress results at design thickness

It has been found that the four points A, B, C and D shown in fig. 8 represent the worst locations from the stress point of view.

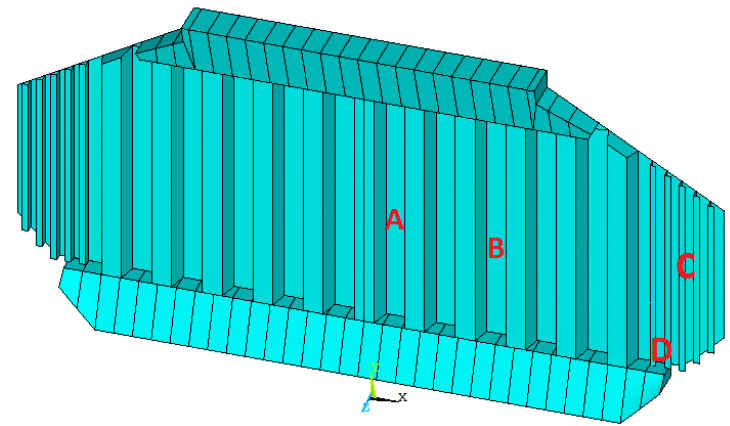

Fig.8. The four considered locations

Fig. 9 presents the relations between the ratio of actual stress to yield stress and the percentage of thickness deduction due to age deterioration at the specified four locations. If a factor of safety equal to $1.2\left(\sigma / \sigma_{y}=0.83\right)$ is adopted, the critical thickness deduction may then be depicted for each location. This deduction ratio is found in the range from 0.28 to 0.3 for the fore end bulkhead considered. Applying the relation of age deterioration according to the corrosion model of Paik [10] and the estimated corrosion rates of the DNV casualty report [11], it can be concluded that the part under consideration should be conveniently repaired after 17 years as shown in table 2 .

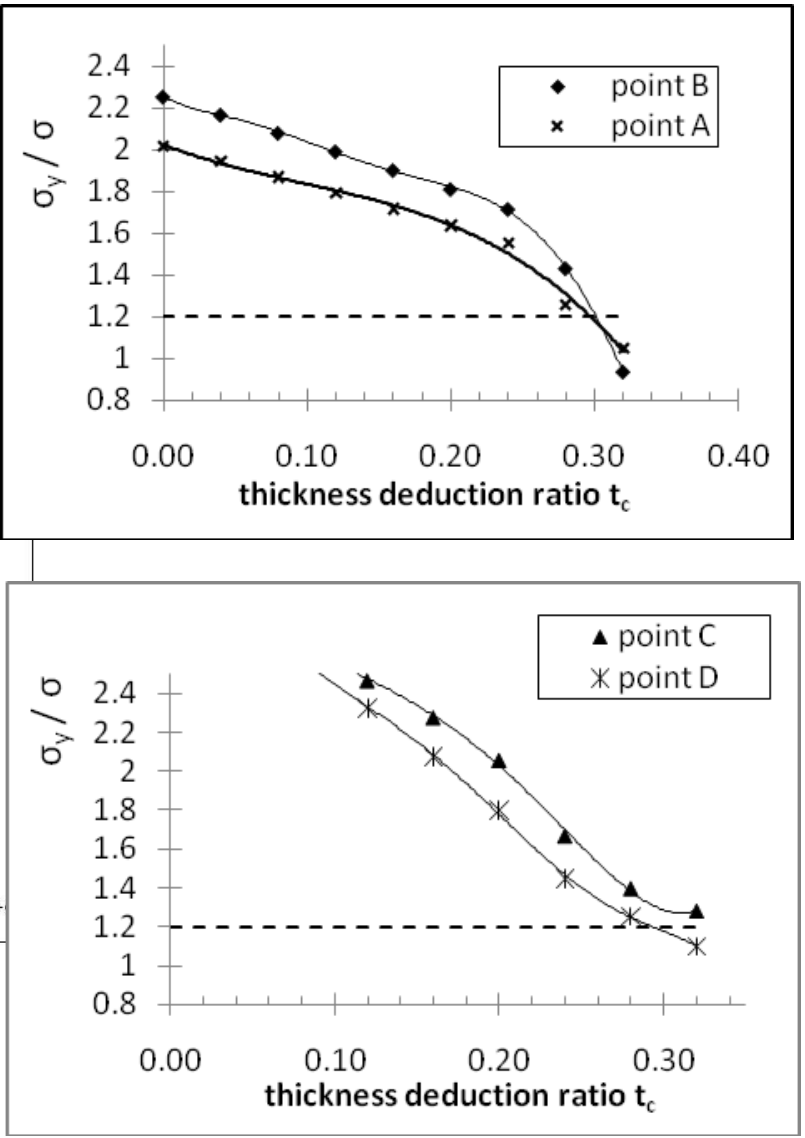

Fig.9. Relation between stress and thickness deduction at different locations. 
Table.2.

\begin{tabular}{|c|c|c|c|c|}
\hline Points & A & B & C & D \\
\hline $\begin{array}{c}\text { Distance } \\
\text { from CL }\end{array}$ & 3.15 & 2.72 & 13.14 & 11.64 \\
\hline $\begin{array}{c}\text { Distance } \\
\text { from keel }\end{array}$ & $\vee . \varepsilon q$ & $\wedge .7 \varepsilon$ & $\vee .01$ & $\varepsilon . \cdot \varepsilon$ \\
\hline $\begin{array}{c}\text { Critical } \\
\text { deduction\% }\end{array}$ & 0.28 & 0.30 & - & 0.27 \\
\hline Years & 17.8 & 18.7 & - & 17.3 \\
\hline
\end{tabular}

\section{CONCLUSIONS}

- The fore end bulkhead is a risk control option according to the formal safety assessment of bulk carriers.

- Ship structural analysis can work as guideline for surveyors to predict the locations to be inspected during each survey).

- The finite element method is a powerful tool that can be used to model the corrugated bulkhead under consideration taking into account an assumed thickness deduction.

- A wastage rate $0.3-0.4 \mathrm{~mm}$ per year may be adopted as a good estimation for the fore end bulkhead with coating effective period five years.

- The proposed approach is applied to an existing bulk carrier and has been found that the critical thickness deduction range is from 0.28 to 0.3 for fore end bulkhead.

- A structural management approach based on related risk control options given by the formal safety assessment would help the ship owner to arrange a proper dry dock maintenance plan.

\section{REFERENCES}

[1] IACS, International Association of Classification Societies, Bulk carriers Guidance and information on bulk cargo loading and discharging to reduce likelihood of over stressing the hull structure, 1997.

[2] ISSC, Committee V.6, condition assessment of aged ships and offshore structures, Vol. 2. $17^{\text {th }}$ International Ship and Offshore Structures Congress, Seoul, Korea, 16-21 August 2009.

[3]IMO, Guidelines for formal safety assessment (FSA) for use in the IMO rule-making process, London: Ref. T1/3.02, MSC/Circ.1023, 5 April 2002.

[4] SOLAS,1974 [Chapter XII], Amendments to the annex to the International Convention for the safety of Life at Sea..

[5] IACS, international association of classification, FSA of Bulk Carriers, Fore-end Watertight Integrity, Annex 2, Bulk Carrier Risks.
[6] MSC72/INF.8. Bulk carrier safety: an interim report on the part of HAZID of FSA on bulk carrier safety, submitted by Japan, February 2000.

[7] Maritime safety committee (MSC) 74/5/X. Bulk carrier safety, Formal Safety Assessment, Fore-end watertight integrity, submitted by IACS, FSA_report.doc,31 May, 2001. Revision 0.

[8] IMO (International maritime organization ). Improving the safety of bulk carriers.

[9] GL. Rules for classification and construction ship technology, seagoing ships, hull structures. Edition 2008.

[10] Paik, J.K., Wang G., Thayamballi A.K., Lee J.M., Time-variant risk assessment of aging ships accounting for general/pit corrosion, fatigue cracking and local dent damage, SNAME annual meeting, San Francisco, USA, 2003

[11] DNV. Casualty information report (Excessive corrosion on transverse bulkheads) No. 2/94, Edited by DSO-245.

[12] Guo. J, et al., A study on reliability-based inspection planning- Application to deck plate thickness measurement of aging tankers, Marine Structures, Vol.25, pp. 85-106,2012.

[13] Servis, D. et al., Finite element modeling and strength analysis of hold No. 1 of bulk carriers, Marine Structures, Vol.16, pp. 601-626, 2003 
